\title{
Schools V.S Institutes in learning a foreign language: For Iranian EFL learners
}

\author{
Mozhgan Alsadat Ghaffarzadeh Hassankiadeh
}

Islamic Azad University, Tonekabon Branch, Iran

Email address:

Ghaffarzadeh.mail@gmail.com

To cite this article:

Mozhgan Alsadat Ghaffarzadeh Hassankiadeh. Schools V.S Institutes In Learning a Foreign Language: For Iranian EFL Learners. International Journal of Language and Linguistics. Special Issue: Language Teaching and Learning Key Principles (LTLKP).

Vol. 1, No. 4-1, 2013, pp. 40-47. doi: 10.11648/j.ij1l.s.20130101.17

\begin{abstract}
This paper aims at describing language educational situations in Iranian schools and comparing the conditions with those ones in Iranian Language institutes. In fact the study concentrates on comparing different educational programs, text books, educational goals and etc. in schools and language institutes. The main aim of the study is to answer this question" what are the main reasons which may lead learners or their parents to trust on language institutes instead of schools to learn a foreign language, i.e. English in Iran?" The answer will assist program designers in schools in editing the design more properly and language teacher/learners to compensate the deficiencies by some substituted techniques which may reduce the failures. Totally the paper concentrates on those missing elements in Iranian language educational program in schools which may have clear effects on its failure or success. Through recognizing them, it will be possible to solve the problems or minimize the deficiencies.
\end{abstract}

Keywords: Institutes, Schools, Learning a Foreign Language

\section{Introduction}

Language is what makes us human. It is the medium we use to share our thoughts with the world (Pick the brain, 2012). The truth is that new thoughts, ideas and technologies are happening all over the world and they are not being immediately translated. In this world Success depends in large measure on the ability of an individual to function as a member of a global village. Learning foreign languages is a necessity. The study of a foreign language helps learners to expand their view of the world, develops their intellect, improves knowledge of the native language (through comparison and contrast with the foreign language), contributes to the development of their personality, and increases their sense of self-worth (St. John's University,2012). So the study of Foreign Languages is increasingly significant nowadays. But the question is how it should be learned. What is the most beneficial way to gain the aim? Is learning a language just learning grammar and vocabulary or it can be learning new sounds, expressions, different cultures and viewpoints. Language learning takes time. So it needs a developed plan to achieve the target. It also requires some instruments such as well-designed plan, syllabus, text-books, tests, educational budget, and enough time. Therefore, to

investigate the success or failure of a language educational process, these tools should be evaluated. In this study, the differences in utilizing these tools between schools and institutes in

Iran are under investigation. In Iran neither the learners and their families nor the teachers believe on the effectiveness of language learning process in schools. Families rely more on institutes for learning and learners devoted parts of their time and their families' budget (if it is possible for their family to afford the expenses) to studying in institutes in summer or even during educational year. The question here is that what the reason of this popularity about the effectiveness of institutes vs. schools in learning a foreign language is. This paper aims at discussing different dimensions of learning/teaching processes in schools vs. institutes to find out the answer. Maybe the answer will assist us to promote the language educational system in schools and to promote its popularity and success among learners/teachers. So some differences between these two language educational systems are presented in the following. 


\section{A Brief Explanation of Teaching / Learning Process in Schools}

Iranian learners should learn a huge amount of words and grammatical points while they don't learn how to use them. In fact the goal of learning a language in schools is to master and memorize a burden of items without considering their usability in real situations. In other words it doesn't matter the learners cannot speak, write or read in foreign languages, the schools' aim is to being able to remind grammatical points and lexical items or to learn testing techniques for obtaining good marks. In most sessions the learners may just write grammatical points in their notebooks and memorize them. It is important to know where a verb should be in a sentence but not to use it in speaking or writing. In some other sessions, they should repeat some phrases or sentences following the teacher and utilize some substitution drills for learning. There is no place for speaking, listening, discussing and using in learning a foreign language. And there is little attention to qualitative writing and reading. Pronunciation and dialogues are covered in books but they are not established well in teaching/learning processes.

\section{A Brief Explanation of Teaching / Learning Process in Institutes}

Each year a lot of learners register in different institutes to learn a foreign language i.e. English in Iran. There are different advertisements and different strategies for each one that is not under investigation here. In this part those aspects which are common in the institutes and make them more popular and successful in front of schools in learning English in Iran is under consideration. Most of their syllabus is based on the sequence of listening, understanding, speaking, reading, and writing. In some of them there is a tendency to teach grammar but grammar is not the center of learning. Learning English here refers to being able to use it not to memorize its items.

Computers or other technologies which can help learners in learning to utilize language will be beneficial here. Most of their text-books are covered by dialogues, listening and speaking practices, pronunciation promotion, and reading and writing development. The culture of target language is considered in their program and learning English is accompanying to being more familiar with its native speakers' culture and values.

\section{Different Text-books}

\subsection{Schools' Books}

English language teaching textbooks play an important role in many language classrooms (Dahmardeh, 2009). The relationship between textbooks and language teaching is not something which has only recently been discussed. In
Iran English text-books are important as teaching a foreign language. With respect to the textbooks in schools, in Iran all of them are produced by the Ministry of Education and no alternatives are available (Dahmardeh, 2009). There are seven books for seven years of language education in the country (each book for one year). The students should begin learning English when they finished primary school. There is one book for each year and the learners/teachers are imposed to use it to learn/teach English. There are a lot of researches about the merits and demerits of these textbooks. For example, Dahmardeh (2009) concluded that "In these text-books each lesson includes a variety of sections such as New Vocabulary, Reading, Speak Out, etc., while each section tries to present only one or two aspects of language. One of the key principles of communicative pedagogy is to teach skills in an integrated manner (Littlewood 1981); and that is because language learning is not learning the language skills solely and separately from each other. On the contrary, it is a combination of all the four skills together".

\subsubsection{New Vocabulary}

There are a lot of words which are listed at the end of each lesson in schools' books. A huge number of new items are collected without being presented in context (a sample vocabulary part retrieved from text-book which is taught in grade three is presented in appendix A to clarify what is explained in the paper). The learners should memorize a burden of new lexicon while they are not familiar with their usability in real or quasi-real situations. Approximately they should learn 250 words in grade three for example in least than eight months. It is really extreme amount of items. It is just about the vocabulary and the condition is the same for other parts of text-books. The only part in which the lexicon included in a conversation mode is the dialogue part which is really artificial for learning and may not be helpful in acquiring language. In fact they are written by non-native speakers and cannot be used as authentic materials. Therefore, it cannot assist learners to gain the goal of promoting their proficiency level. Because the way that teachers mostly use to teach vocabulary in schools may be important in success or failure of the plan, so in next parts it will be explained fully.

\subsubsection{Grammar Part}

Schools' text-books included grammatical parts in which one item is given at a time and mastery of the first is required before moving to another one. As MC Donough (1981) has stated "the transition from one lesson to the other one is intended to enable material in one lesson to prepare the ground for the next. The assumption behind these most grammatical text-books seems to be that language consists of a finite set of rules which can be combined in various ways to make meaning (Nunan, 1998). Rutherford (1987) calls this grammatical plan of learning "accumulated entities" in learning a language. As Nunan (1998:22) concluded these kinds of text-books are under the assumption that learners will automatically use 
language communicatively outside the classroom, if its formal aspects have been internalized. But as he himself (1998:30) declared the evidence from language acquisition research suggests that learning does not occur in such situations. In fact, these types of syllabus concentrate on only one aspect of language i.e. formal grammar. As it is presented in appendix B (the grammatical part of first lesson in schools' book grade three), it is shown that the structure is presented in a deductive way in a diagram and in a theoretical mode to be memorized by learners. In these books it is believed that the learners should master the structure before using it. It is not assumed that learners can learn how to speak and write without directly going through structure.

\subsubsection{Oral Drills and Patterns}

To follow what is assumed in grammatical part, oral drills part is included in the books. In these parts some structures are presented in a substitution drill form and the learners should repeat what they have heard and change the related words based on the structure (a sample part is presented in appendix C). It is declared that this part is constructed based on behaviorism view (habit=learning). The belief is that habit formation will lead to learning. There is no place for meaning, understanding, communicating and acting. It is just mere repetition and memorization.

This section is mainly concerned with speaking plus some grammatical structures. This section presents a grammatical structure followed by some examples. So, the teacher reads them aloud and students are supposed to repeat them and substitute some items in the sentences. The first obvious problem of this section which contradicts the basic principle of CLT is its emphasis on drilling exercises (Dahmardeh, 2009). Nunan (1999: 76) clarified that drills cannot equip the learners to communicate and the learners should be provided with opportunities to use the language creatively.

\subsubsection{Speak Out and Dialogues}

In this section, some questions are presented and the learners are asked to answer them based on what they have already learned in oral drills section. After listening and writing part, this section was presented in schools' books. The direction shows that the learners should look at the pictures in this part and make questions or answer them, following the model.

The first question is why this item was presented after writing part. Is it true to try to write before learning to speak? Besides, the way that this part was utilized in the classroom and the direction which was used during the practice cannot be so much helpful in teaching speaking. In this practice the learners just try to repeat what was presented in the models mostly in written form (A sample of this section is concluded in appendix D).

\subsubsection{Write it down}

In Iranian school books this section was limited to write the proper order of some unscramble sentences or filling the blanks based on the given models. Having a glance at this part, no communicative performance can be seen. There is no real or near-real environment in the section. No attention is given to writing abilities and qualification (see appendix E, write it down part in Iranian school books).

\subsubsection{Reading}

This part was prepared really artificially in school books. There is no story-like procedure, communicative competence, attractiveness and solidarity in the texts. In fact using grammatical points were preferred to the stated qualifications. It is no matter not to have a communicative and attractive text in a real context, the important goal is to utilize structural points even in expense of making a boring text (see appendix F, reading part in Iranian school books).

\subsection{Institutes' Books}

Considering textbooks as one of the most beneficial instruments in achieving educational aims, special attention should be given to designing and preparing it properly. As Cunnigsworth (1984) said "course materials should be seen as teachers' servants and not his master". In the following the elements of institutes books (the most similar parts) will be discussed in details.

\subsubsection{New Vocabulary}

In most of the institute books, there is no separate part for collected vocabulary items. Lexicon should be learned during speaking, listening, reading or writing. While communicating, new vocabulary will be produced or received. And here real learning will occur.

\subsubsection{Grammar Part}

In some of the new institute books no clear stating of structure is believed. But some others believe on describing the grammatical point but by utilizing example sentences and after making learners familiar with them during listening, speaking, reading or writing. No memorization is needed. Grammatical notes just should use as a reminder (see appendix G, grammar part of an institute book).

\subsubsection{Oral Drills and Patterns}

So, one of the suggestions in order to teach grammatical structures might be introducing them by practicing authentic conversations. For instance, in order to practice past tense, teachers might ask two students to talk about activities that they have done previously, after exposing them to an authentic conversation between two friends who talk about the activities that they did before. It is necessary to keep it in mind that the learners should not be required to imitate the same conversation. The advantage of this type of practice is that the students are free to choose meaningful answers which would also make the activity authentic and more interesting.

Meanwhile, the introduced grammatical item might be picked up by the learners automatically. Also, in order to make sure about students' thorough understanding of the 
new structures, the teacher can simply try to assess students' acquired knowledge by modifying the exercise and practicing some other types of exercise which would still include the same grammatical structure.

\subsubsection{Speak Out and Dialogues}

Dialogues are popular activities in ESL text books for a number of linguistic as well as cultural reasons (drills \& dialogues, 2012). Dialogues are used usually to show spoken language in a special context. Dialogues are useful for listening to and practicing pronunciation and other phonological features (drills \& dialogues, 2012). So paying enough attention to this part is necessary for learning a language. It should be occurred in real or quasi real situation, talking about real and interesting things related to learners' needs. In most of the institute books, these kinds of dialogue were covered (see Appendix H, a sample dialogue in institute books). The dialogues are about attractive events in human lives, the topics which may engage learners in learning. The dialogues were presented in a sequence of listening and practicing not just memorizing (in schools' books). And the learners will produce similar situational dialogues about themselves and practice them.

\subsubsection{Write it Down}

Writing is a significant skill which should be considered as a critical stage in learning/teaching a language. Writing should be taught communicatively to assist learners to be able to write his/her own journal in that language and help them in communicating via using it. It shouldn't be an artificial stage which is used just to find the proper order of an unscramble sentence for example (see appendix I, a sample writing part in institute books).

\subsubsection{Reading}

Reading is a complex activity that involves both perception and thought (Pang, et al, 2003). It consists of recognizing and comprehending written symbols which is related to spoken language. Learning to read is an important educational goal (Pang, et al, 2003). It

is taught to assist learners' to utilize reading in real life situations, such as reading a newspaper, magazine, manual, map, etc. reading instruction needs to take into account different types of learners and their needs (Pang, et al, 2003). So learners' different needs in different social situations or making familiar with various cultures should be considered in applying a proper and appropriate comprehension text. Reading texts should develop reading skills through using authentic materials. It should prepare learners for real future life not for an artificial one. A sample of texts which may be used in institutes was prepared as appendix $\mathrm{J}$. In this text, an interesting real-like story with real emotions was presented to help learners to develop reading skills through communicating with an authentic material.

\section{Different Goals and Desires to Learn}

Compare the following kinds of learners and teachers in educational programs:

1. The learners in a language classroom have different language levels and desires to learn. Some of them are highly fluent; some in the intermediate level and the others are beginners. There are a lot of learners in one class that have no desire to learn English. In this situation there is no chance for selecting to learn or not to learn. They are imposed to attend the language class. The teachers in this situation are expected to increase learners' ability in structural recognition and memorizing skills. They are not free to choose the procedures and text-books, too. As Namaghi (2006) stated "there are sociopolitical forces which help determine teachers' work in Iran."

2. In this group learners will classify based on their language levels in different classes. Most of the learners are eager to learn the target language. They can choose a language institute and consequently a desired text-book or even teacher for learning a language. They can leave the institute when they aim at. And they aren't imposed to attend the language classes. Even it can be said that most interested learners will attend the institutes to learn languages. Teachers in this group are as free as the learners. They can select the institute, text-books or even the learners that they desire to teach. They can teach the ones that cover their beliefs as much as possible. They can change their institutes even. There is no powerful authority which may limit teachers and learners in a way that may hurt teaching/learning processes.

\section{Free and Closed Hands}

As it was stated in previous parts, there are several elements in schools and institutes which may lead the learners/teachers to different educational outcomes. In the following, some of them will be explained in details.

\subsection{Time Limitation}

In schools time is very limited. In first three levels $(1,2$, \&3 Guidance school) there are 2, 4 and 4 hours in a week respectively. And in second four levels (1, 2, 3 and 4 ), the devoted time is $4,4,4,2$ in a week respectively . Four hours in a week means 2 sessions which each one will be equal to 1 hour. I mean the real devoted time in a 4 hours level is 2 hours in fact ( 4 hours minus the devoted hours to other programs in the class). And for a 2 hours class it will be reduced to one hour in a week. And it is expected to dedicate this time to teaching structural points of the book.

\subsection{Budget Limitation}

Another problem in the schools is budget limitation which the institute aren't confronted with it so much. The learners should pay some intuition to institutes but not to most of the schools. Budget limitation may lead to 
decreasing the quality of teaching facilities. And it may lead to reduce the quality of learning consequently.

\subsection{Norm-Based V.S. Ability Based Programs}

Most of the Iranian schools have norm-based programs in teaching a subject (also a language). It is the criteria that will show the learners' ability in that subject. There is no attention to language ability development and measurement. No proper concentration on producing and using language or communicating through it. Consequently there is no measuring program to identify this language production level in educational situations. But in most of the institutes it is vice versa.

\section{Different Plans to Learn (Acting V.s. Memorizing)}

Success of an educational plan depends on the aims which are considered to reach during the program. In Iranian schools, the fundamental goal is being able to remind the lexical items and grammatical points., to read a text accurately, to find the best answer in a multiple-choice test and to recognize the best matching method for ordering an unscramble dialogue. The missing areas are being able to speak and write fluently and accurately, to recognize spoken language (listening skill), to be familiar with target culture and customs which will help learners in communicating to native or near- native speakers, to transfer information from one language to another. And it should be the final aim of teaching/learning a foreign or second language. It is done in most of the Iranian language institutes to some extent.

\section{Different Learning Measurements}

Success of an educational plan will also be connected to the different measuring instruments and the aims for measuring. If the goal of the final test is just to measure learners' structural strength or weaknesses, we shouldn't expect to train strong learners in speaking and writing skills for example. Surely they cannot be the representatives of those learners who can communicate via language, if they just passed the final exam of language tests in schools.

\section{Different Teaching and Learning Procedures}

Another significant issue in determining the success or failure of an educational program is the differences between teaching procedures which will be used by different educational situations. Some habits may be formed some teachers in a way in which they may utilize them in the language classrooms. For school teachers in Iran, some limitations and expectations may impose teachers to behave in different manner than those ones in language institutes. These different situations may lead to different habit-forming in teachers' minds. Some instances of these habits are drilling, repeating, memorizing , .... .Most of Iranian school teachers believe in using memorization and rote learning regarding learning a foreign language. And those ones who don't believe it, should accommodate themselves to it because the final exam and other educational expectations were presented based on this belief. In the situation which speaking, writing, communicating and producing aren't significant issues in learning a language, we cannot expect to have fluent and accurate producers (learners) after passing the specified language classes. In institutes in spite of schools, most of the language teachers believed in helping to learn, teaching how to learn and assisting in producing and communicating. In their beliefs the final goal is being able to communicate in the target language (to use it), not knowing about its elements (to analyze it).

\section{Culture, the Forgotten Part}

As it was explained in previous segments of this paper, culture is the missing part in Iranian schools language books. There is no attention to culture acquiring via learning a language. In fact neither in books, nor in teachers' minds, there is no clear place for teaching the culture of the target language. Even though in some parts of school books, there are some Iranian culture advertisements through using a foreign language (i.e. English in Iran). The Iranian names, Iranian families, Iranian heroes are who make the texts in the school books. But in language institutes books, there is definite attention in showing target culture while teaching language.

\section{How to Fill the Gap}

Most of the elements which make differences between schools and institutes cannot be changed based on the Iranian educational programs because it is the rule of Iranian teaching and training ministry and may not be added or omitted by the teachers or learners themselves. So in current situation we should neglect them and apply in the parts which can be edited by us. It is true that the textbooks were not designed based on communication - based programs, but the procedure may not to be books' slaves as Ghorbani stated (2009). Although Jahangard (2007) has stated that students' aural and oral skills are not emphasized in Iranian ELT text-books, but we can use different strategies to get free from limitations of books to some extent. Teachers can utilize some communicative games or musical plays to change the bored situation to the most interesting one. It is obvious that we cannot be successful in front of institutes until the basic programs of the Iran educational ministry is stable but it is possible to reduce its deficiencies as much as is possible. 


\section{Implication and Conclusion}

The deficiencies of school materials and text-books, budget limitation, learners' different desires, teachers' closed hands in choosing and changing and other problems caused to have a clear failure in teaching/learning a foreign language in front of language institutes in Iran. In fact in reality there is very little focus on uses of English in reallife situations (Ghorbani, 2009). The different expectations and rules in language educational program will lead to such huge differences in reality. The teaching/learning situation

\section{Appendix A}

Vocabulary part in schools book in Iran (Book3)

$\begin{array}{ll} & \text { New Words And Expressions } \\ \text { beautiful } & \text { bus - stop } \\ \text { big } & \text { eraser } \\ \text { easy } & \text { garden } \\ \text { fat } & \text { ground } \\ \text { good } & \text { ice-cream } \\ \text { hard } & \text { know } \\ \text { large } & \text { leg } \\ \text { long } & \text { look like } \\ \text { new } & \text { near } \\ \text { old } & \text { of } \\ \text { short } & \text { one } \\ \text { small } & \text { people } \\ \text { tall } & \text { perhaps } \\ \text { thin } & \text { roof } \\ \text { young } & \text { sandwich } \\ & \text { some } \\ & \text { that } / \text { this one } \\ & \text { them }\end{array}$

\section{Appendix B}

Grammar part in schools book in Iran (Book3)

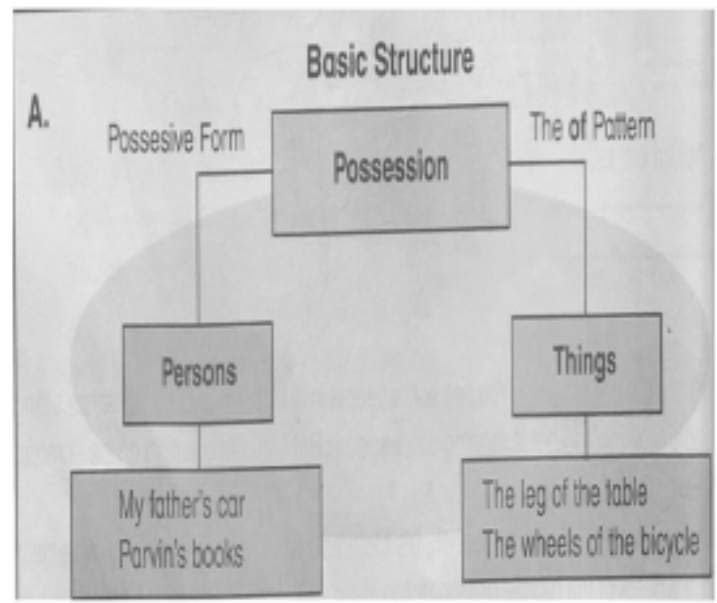

is authorized by government and is not available to edit it freely and easily but teachers and learners can reduce these deficiencies by using interesting and authentic materials while teaching /learning processes. They can use texts of the books in different ways. They can make their own. Even the teachers can ask learners to find deficiencies of text-books or educational situation and try to assist each other to confront with it and decrease them as much as possible. But if the government helps them in this editing process, it can be achieved better and sooner than expected.

\section{Appendix C}

Oral drills part in schools book in Iran (Book3)

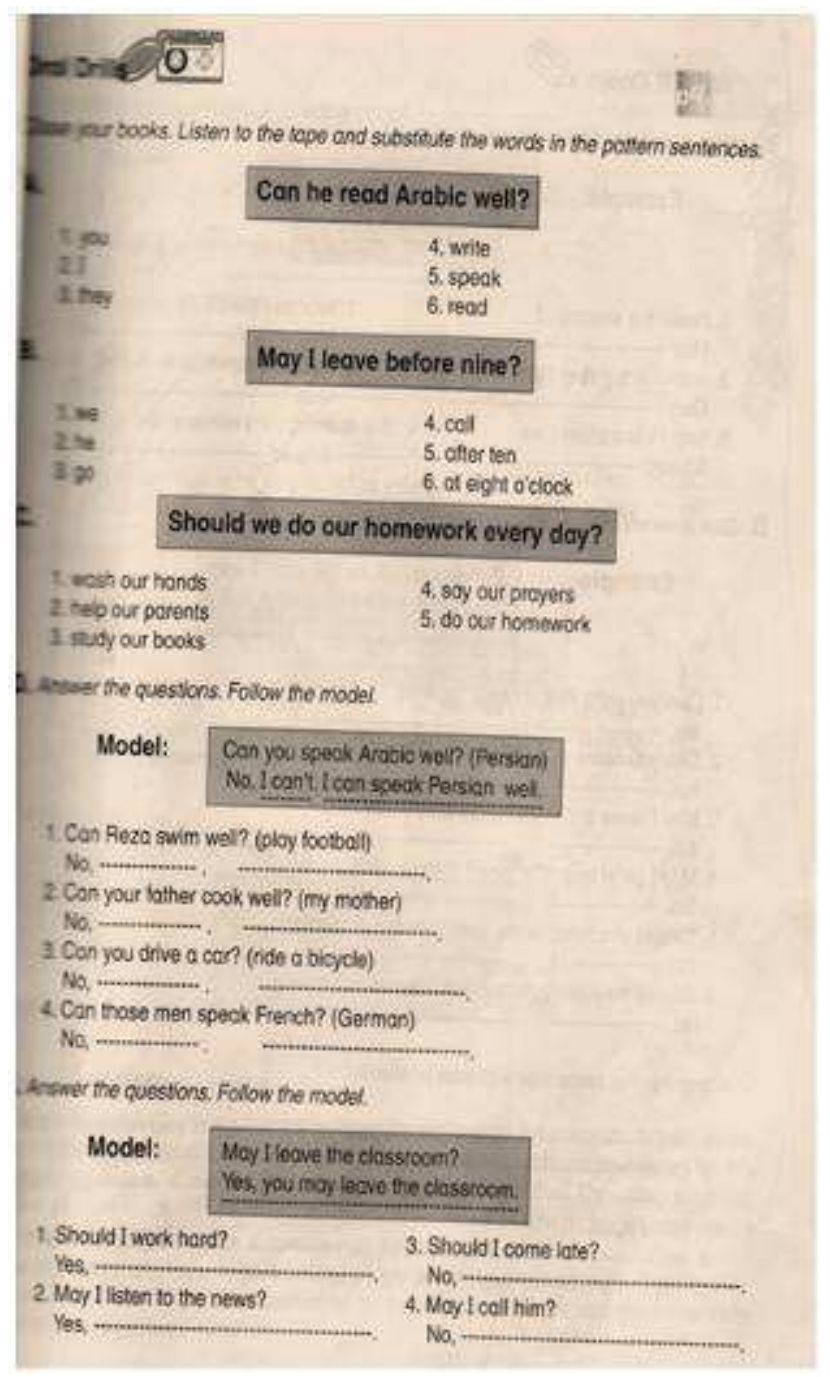




\section{Appendix D}

Speak out part in schools book in Iran (Book3)

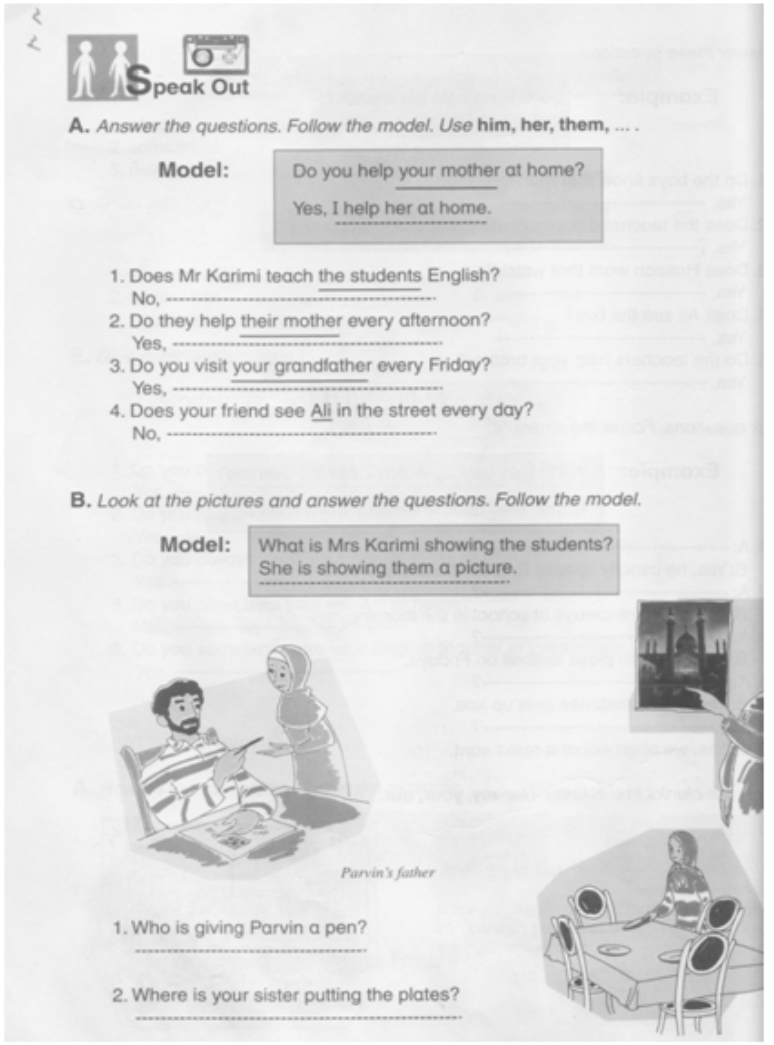

\section{Appendix E}

Write it down part in schools book in Iran (Book3)

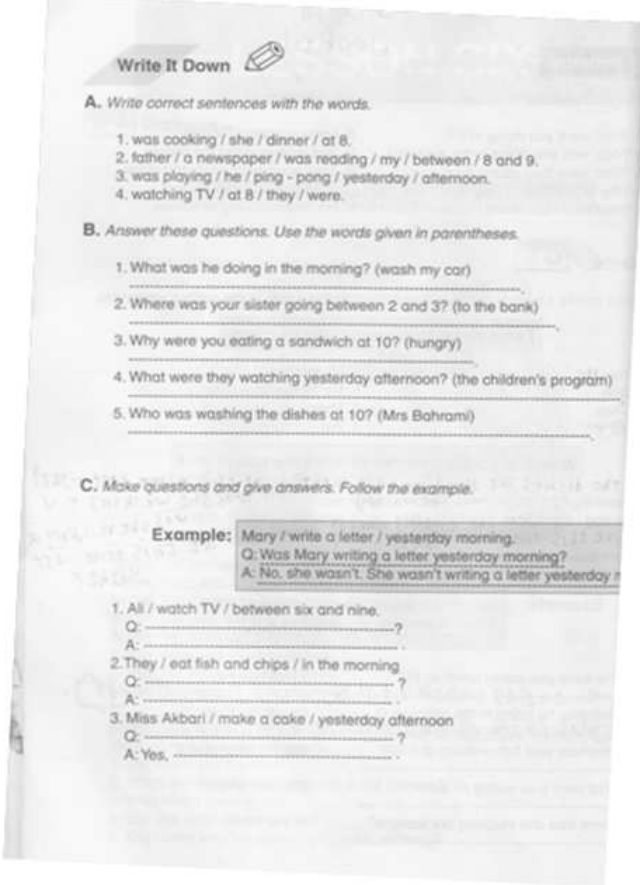

\section{Appendix F}

Reading part in schools book in Iran (Book3)

Mr Kamali and his family are from Tehran. They now live in Birjand. They had a difficult life in Tehran. They think people in small towns have a happy life. They don't have many of the problems that people have in big cities. There are not many cars in the many of the prob don't spend a lot of time in the heavy traffic every day. They can get the streets. And they donit spend fast. People are not always in a hurry. They have a tot of free things they need easily and fast. People ariends. People are not very busy in small towns. -time. They can visit their relatives and triend

Now answer these questions.

1. Where is Mr Kamali from?

2. Where is he living now?

3. Does he enjoy his life in Birjand?

4. Is life easy in big cities?

5. Are people busy in small towns?

\section{Appendix G}

Grammar part in a sample of institute books in Iran (Interchange 3)

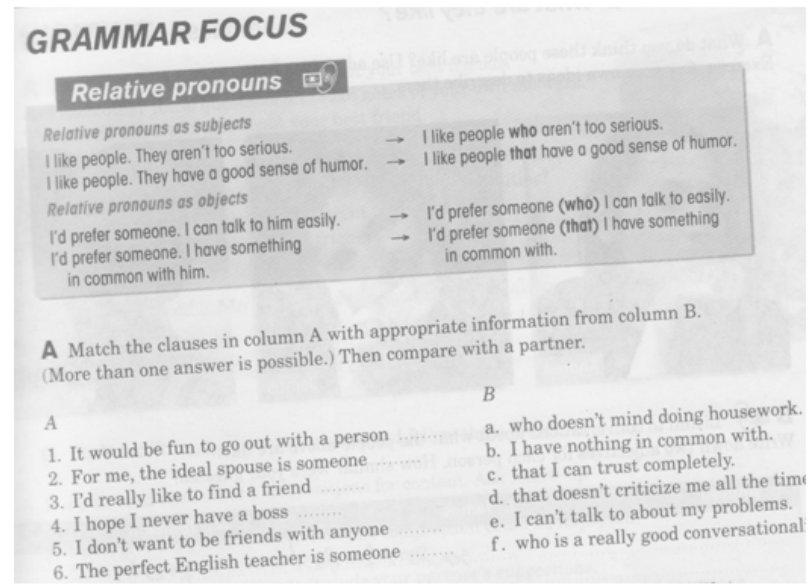

\section{Appendix H}

Dialogue part in a sample of institute books in Iran (Interchange 3)

\section{CONVERSATION}

A $\mathbf{⿴ 囗 十}$ Listen and practice.

Chris: Do you have a date for the party yet? Kim: Actually, I don't. ... Do you think you could help me find one?

Chris: Hmm. What kind of guys do you like? Kim: Oh, Ilike guys who aren't too serious and who have a good sense of humor. You know, ... like you.

Chris: OK. What else?

Kim: Well, Id prefer someone I have something in common with - who I can talk to easily. Chris: I think I know just the guy for you. Bob Branson. Do you know him?

Kim: No, I don't think so,

Chris: Let me arrange for you to meet him, and you can tell me what you think.

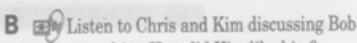

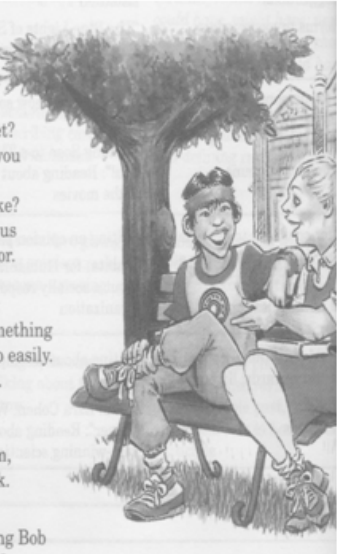
after Kim met him. How did Kim like him? 


\section{Appendix I}

Writing part in a sample of institute books in Iran (Interchange 3)

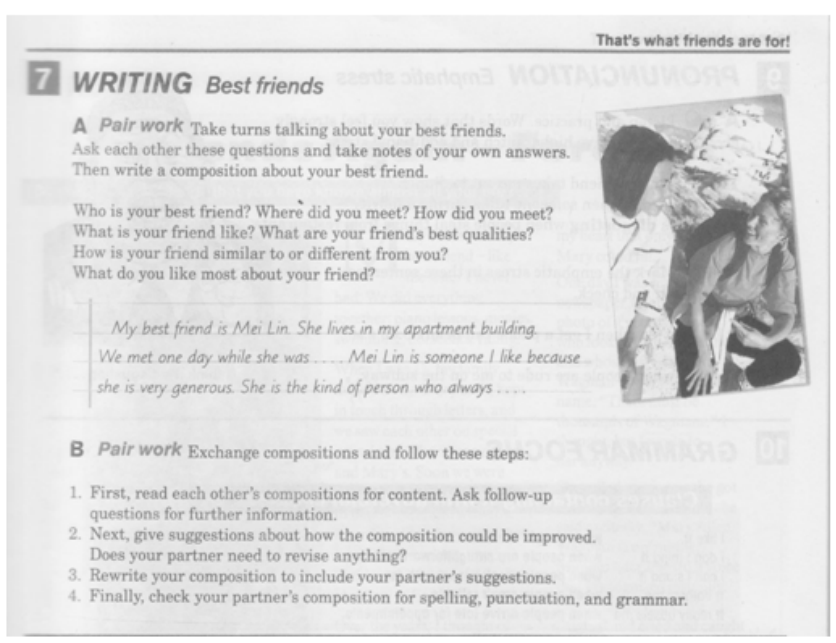

\section{Appendix J}

Reading part in a sample of institute books in Iran (Interchange 3)

\section{READING}

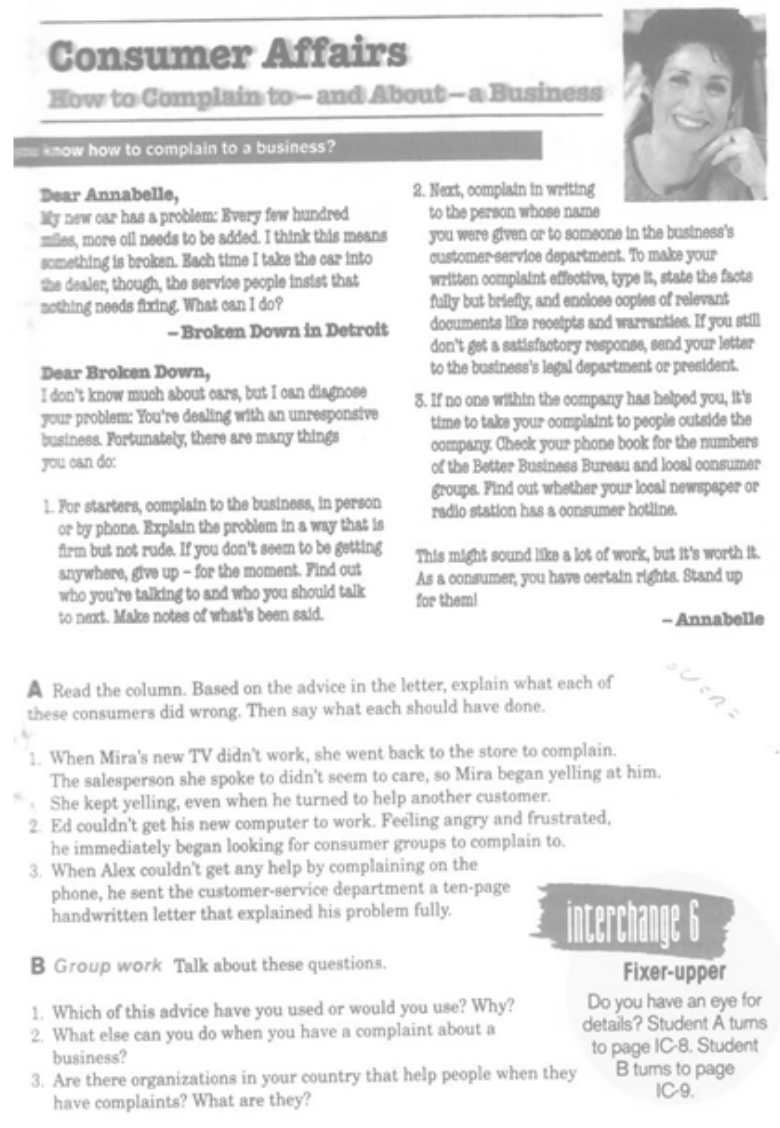

\section{References}

[1] Cunnigsworth, A.1984. Evaluating and selecting EFL teaching materials. London: Heinemann Educational Books.

[2] Dahmardeh, M. 2009. Communicative textbooks: English language textbooks in Iranian secondary school. Linguistic online 40, 4/09. Available on: http://www.linguistik online.de/40_09/dahmardeh.html

[3] Drills, dialogues and role plays. 4 April 2012. The university of Michigan Press. Available on : http://www.press.umich.edu

[4] Ghorbani, M,.R.2009. ELT in Iranian High Schools. The journal of reflections on English language teaching, 8(2),131-139.

[5] Jahangard, A. 2007. Evaluation of EFL materials taught at Iranian public high schools. The Asian EFL journal, 9(2), 130-150.

[6] MCDonough, S.1981. Psychology in Foreign Language Teaching. London :Allen and Unwin.

[7] Namaghi, S.,A. 2006. Forces seeing language teachers' work in public high schools in Iran. The Reading Matrix , 6(2), 90-105.

[8] Nunan, D. 1998. Syllabus Design: A scheme for teacher education. Oxford University Press.

[9] Nunan, D. 1999. Second language learning and teaching. Boston.

[10] Pang,S., Elizabeth, Muaka.,Angaluki, Bernhardt,B.,Elizabeth, andKamil, L., Michael.2003. Teaching reading. International academy of education (IAE). Distributed by

[11] International Bureau of Education andAcademy. University of Illionios, Chicago.

[12] Pick the Brain.2012. Retrieved on August 14, 2012. Available on: http://www.pickthebrain.com/blog/5-greatreason-to-learn-a-foreign-language/

[13] Rutherford, W. 1987. Second Language Grammar: Learning and Teaching. London: Longman.

[14] St.John's University. 2012. Retrieved on August 14, 2012. Available on: http://www.stjohns.edu/academics/graduate/liberalarts/depar tments/languages/why.stj 